\title{
PENGARUH KOMUNIKASI TERHADAP KINERJA PEGAWAI PADA BADAN KEPEGAWAIAN KABUPATEN TAMBRAUW
}

\author{
Putu Anggreyani Widya Astuty. \\ Universitas Victory Sorong \\ Email: putuwidya815@gmail.com
}

Diterima:10 April 2016. Dipublikasikan: 1 Juni 2016

\begin{abstract}
ABSTRAK
Kemampuan suatu organisasi dalam menghadapi tantangan era millennium tergantung pada kemampuan mobilisasi sumber daya manusia. Karakteristik yang menentukan dari sistem organisasi terletak pada sifat dalam mencapai sasaran. Sumber daya manusia dan perangkat kerja pada umumnya di organisasi untuk mencapai tujuan -tujuan organisasi yang dinyatakan jelas. Komunikasi yang baik tidak hanya berbicara ataupun surat-menyurat saja, meskipun organisasi perkantoran telah menggunakan alat-alat komunikasi yang mutahir dan memiliki pimpinan pandai berbicara yang dapat menyampaikan dengan cepat seluruh instruksi-instruksi, petunjuk, saran dan sebagainya, akan tetapi hal ini belum menjamin bahwa komunikasi telah dilakukan dengan baik. Peran pimpinan secara keseluruhan sangat signifikan dalam upaya tersebut, dimana kualitas sumber daya manusia sebagai aparatur pemerintah harus dijadikan motivator dalam mengkoordinir dan mengorganisir pegawai sehingga mampu berkomunikasi secara baik dalam era globalisasi saat ini. Populasi dalam penelitian ini adalah pegawai pada Badan Kepegawaian Tambrauw yang berjumlah 14 pegawai. Sampel yang penulis gunakan yaitu merupak sampel populasi yaitu sampel yang menggunakan seluruh populasi sampel, yaitu yang berjumlah 14orang pegawai. Metode analisis yang digunakan oleh penulis adalah dengan menggunakan korelasi product moment. Hasil penelitian yang diperoleh penulis adalah sebesar 0,74. Yang artinya bahwa ada hubungan yang tinggi sekali antara pengaruh komunikasi terhadap kinerja pegawai pada Badan Kepegawaian Kabupaten Tambrauw.
\end{abstract}

Kata Kunci : Komunikasi dan Kinerja Kerja Pegawai 


\section{Sentralisasi Volume 5(2): 15-20 (2016)}

Pengaruh Komunikasi Terhadap Kinerja Pegawai Pada Badan .......

Putu Anggeyani Widya Astuty

\section{PENDAHULUAN}

Kemampuan suatu organisasi dalam menghadapi tantangan era millennium tergantung pada kemampuan mobilisasi sumber daya manusia. Karakteristik yang menentukan dari sistem organisasi terletak pada sifat dalam mencapai sasaran. Sumber daya manusia dan perangkat kerja pada umumnya di organisasi untuk mencapai tujuan -tujuan organisasi yang dinyatakan jelas.

Kekuatan suatu organisasi terletak pada manusianya, bukan pada sistemnya, untuk membentuk suatu kerjasama yang baik jelas perlu adanya komunikasi yang baik antara unsur-unsur yang ada dalam organisasi tersebut. Komunikasi yang baik akan menimbulkan saling pengertian dan kenyamanan dalam bekerja sesuai dengan kenyataan tersebut seberapa besar fungsi komunikasi berperan dalam organisasisering diabaikan.

Menurut Pace dan Faules (2000: 72) komunikasi adalah dalam sebuah organisasi memiliki pengertian yaitu informasi mengalir dari jabatan berotoritas lebih tinggi kepada mereka yang berotoritas lebih rendah.

Komunikasi yang baik tidak hanya berbicara ataupun surat-menyurat saja, meskipun organisasi perkantoran telah menggunakan alatalat komunikasi yang mutahir dan memiliki pimpinan pandai berbicara yang dapat menyampaikan dengan cepat seluruh instruksiinstruksi, petunjuk, saran dan sebagainya, akan tetapi hal ini belum menjamin bahwa komunikasi telah dilakukan dengan baik. Hal ini member pengertian bahwa dalam organisasi yang telah menggunakan alat-alat komunikasi yang modern dan pimpinan yang pandai berbicara dapat saja terjadi miss communication dan miss understanding.
Oleh karena itu, untuk mewujudkan kselarasan kerja dalam memenuhi dua kepentingan masing-masing anggota organisasi diperlukan kerja sama antar pegawai. Sumberdaya manusia sebagai potensi organisasi yang terbesar mau tidak mau harus bekerja secara kelompok dengan karakteristik individual yang berbeda. Untuk itu, didalam menumbuhkembangkan organisasi yang berlandaskan kerjasama atau kolektifitas kelompok diperlukan adanya kinerja serta struktur organisasi bekerja secara efektif. Hal ini berkaitan dengan motivasi seseorang dalam melaksanakan pekerjaannya. Kecendrungan seseorang melakukan pekerjaannya. Kecendrungan seseorang melakukan pekerjaan yang baik ataupun buruk merupakan tujuan motivasinya dalam memenuhi kebutuhan hidup. Jadi untuk kelancaran pencapaian tujuan motivasinya dalam memenuhi kebutuhan hidup. Jadi untuk kelancaran pencapaian tujuan organisasi perlu adanya semangat kerja dari unsure-unsur yang ada dalam organisasi. Semagat kerja atau motivasi kerja yang timbul dalam diri seseorang akan mendorong manusia sebagai unsure organisasi akan berpengaruh terhadap efektivitas dan efisiensi kerjanya.

Secara spesifik, tujuan dari evaluasi kinerja sebagaimana dikemukakan Agus Suyanto dalam A. A. Anwar Prabu Mangkunegara (2005 : 9) adalah meningkatkan saling pengertian antara pegawai tentang persyaratan kinerja. Mencatat dan mengakui hasil kerja seseorang pegawai sehingga mereka termotivasi untuk berbuat yang lebih baik atau sekurang-kurangnya berprestasi sama dengan prestasi yang dulunya.

Dalam rangka mewujudkan cita-cita dan tujuan bernegara dan berpemerintahan yang baik (good govermance), sesuai dengan tuntutan nasional dan tantangan global, diperlukan 


\section{Sentralisasi Volume 5(2): 15-20 (2016)}

\section{Pengaruh Komunikasi Terhadap Kinerja Pegawai Pada Badan ........}

Putu Anggeyani Widya Astuty

sumberdaya manusia aparatur yang memiliki jabatan dalam penyelenggaraan Negara dan pembangunan. Bahwa untuk membentuk sumber daya manusia aparatur yang memiliki kompetensi sebagiamana dimaksudkan diperlukan komunikasi yang baik antara atasan dan bawahan.

Begitu juga dengan Badan Kepegawaian Kabupaten Tambrauw dalam hal berkomunikasi. Peran pimpinan secara keseluruhan sangat signifikan dalam upaya tersebut, dimana kualitas sumber daya manusia sebagai aparatur pemerintah harus dijadikan motivator dalam mengkoordinasi dan mengorganisir pegawai sehingga mampu berkomunikasi secara baik dalam era globalisasi saat ini. Hal ini juga disebabkan bukan hanya karena masalah komunikasi melainkan buruknya kinerja pegawai yang diketahui dari.

1. Kepuasan kerja

2. Disiplin kerja

3. Kerjasama

4. Kualitas kerja

Keempat hal tersebut diatas muncul akibat kurangnya komunikasi pegawai dimana :

1. Keterbukaan antara atasan dan bawahan

2. Kejelasan perintah lewat komunikasi

3. Komunikasi dalam memberikan informasi

4. Komunikasi dalam memberikan motivasi.

Dengan demikian dari uraian latar belakang diatas dimana komunikasi menjadi hal terpenting dalam sebuah organisasi. Organisasi yang berhasilapabila didukung dengan manusia yang memiliki potensi sumber daya manusia dalam hal ini mampu berkomunikasi dan memberikan pesan kerja kepada orang lain untuk dapat dimengerti dan dilaksanakan dengan sebaik-baiknya. Untuk itu, organisasi dapat berjalan dan mencapai tujuan tergantung pada peran sumberdaya yang handal, sebab manusia dan organisasi tidak terlepas dari komunikasi yang baik pula

Berdasarkan latarbelakang masalah diatas maka penulis tertarik melakukan penelitian dengan judul "Pengaruh Komunikasi Terhadap
Kinerja Pegawai Pada Badan Kepegawaian Kabupaten Tambrauw".

\section{Tujuan dan Manfaat Penelitian}

\section{Tujuan Penelitian}

Berdasarkan latar belakang diatas maka dapat didiskripsikan sebagai tujuan penulisan skripsi ini sebagai berikut :

a. Untuk mengetahui bagaimana peran Kepala Badan Kepegawaian dalam upaya meningkatkan kualitas komunikasi yang baik antar pegawai di lingkungan Kabupaten Tambrauw.

b. Untuk mengetahui efektif tidaknya proses komunikasi yang mempengaruhi komunikasi antar pegawai.

c. Untuk mengetahui sejauhmana penerapan komunikasi antar pegawai, serta dalam melaksanakan tugas pelayanan kepada masyarakat.

\section{Manfaat Penelitian}

Hasil penelitian ini diharapkan dapat memberikan manfaat sebagai berikut :

a. Sebagaimasukan (input) dan informasi bagi pihak Pemerintah dalam hal ini instansi terkait Badan Kepegawaian selaku peyelenggaraan komunikasi antar pegawai dalam rangka meningkatkan sumber daya pegawai dalam berkomunikasi secara efektif.

b. Sebagai proses pembelajaran bagi dalam menimbah ilmu pengetahuan.

c. Sebagai informasi dan referensi bagi masyarakat atau pembaca demi pengembangan ilmu pengetahuan serta pembekalan bagi yang berminat melakukan penelitian ini.

\section{Hipotesis}

Komunikasi atasan bawahan merupakan factor utamayang dapat mempengaruhi kinerja kerja pegawai pada umumnya. Maka hipotesis yang penulis angkat yaitu : 
diduga bahwa apabila komunikasi dilakukan dengan baik maka akan meningkatkan kinerja pegawai pada Badan Kepegawaian Kabupaten Tambrauw.

\section{METODOLOGI PENELITIAN}

Jenis penelitian yang penulis gunakan dalam penelitian ini adalah penelitian deskriptif kuantitatif. Penelitian deskriptif adalah suatu penelitian yang ditujukan untuk menggambarkan fenomena-fenomena yang ada, yang berlangsung saat ini atau saat yang lampau. Penelitian deskriptif, bisa mendeskriptifkan keadaan dalam tahapantahapan perkembangannya.

Populasi yang akan diambil oleh penulis dalam melakukan penelitian adalah Badan Kepegawaian Kabupaten Tambrauw yang berjumlah 14 Orang pegawai. Dalam metodologi penelitian ini, penulis menggunakan teknik pengumpulan sampel ini dilakukan dengan menggunakan sampel populasi yaitu semua populasi dilibatkan untuk menjadi sampel, yaitu Badan Kepegawaian Kabupaten Tambrauw yang berjumlah 14 Orang pegawai.

Metode analisis yang digunakan adalah analisis deskriptif dengan bantuan tabel tanggapan responden tentang komunikasi dan kinerja kerja pegawai dan menggunakana rumus korelasi product moment :

$$
r=\frac{n \cdot \sum X Y-\sum X \sum Y}{\sqrt{n \sum X^{2}-\left(\sum X\right)^{2} \cdot n \sum Y^{2}-\left(\sum Y\right)^{2}}}
$$

Keterangan :

$\mathrm{r}=$ koefisien korelasi

$\mathrm{n}=$ banyaknya responden

$\mathrm{Y}=$ Skor dalam distribusi variabel $\mathrm{Y}$

$\mathrm{X}=$ Skor dalam distribusi variabel $\mathrm{X}$

\section{HASIL DAN PEMBAHASAN \\ Deskriptif Data Responden}

Kuisioner yang disebarkan 14 responden, semua kuisioner memenuhi kriteria. Karakteristik responden yang menjadi subjek dalam penelitian ini terdiri dari, jenis kelamin, umur, pendidikan. Dalam kuisioner responden tidak perlu mencantumkan identitas pribadi atau nama untuk kerahasiaan informasi yang diberikan responden.

a. Karakteristik Responden Berdasarkan Jenis Kelamin

Berdasarkan dari jenis kelamin,pegawai dibagi menjadi dua yaitu laki-laki dan perempuan. Dari hasil kuisioner yang disebarkan ditemukan bahwa pegawai lakilaki lebih dominan dibandingkan dengan perempuan. Dari hasil pengolahan data dapat dilihat bahwa pegawai yang berjenis kelamin laki-laki sebanyak 9 orang dengan tingkat persentase $64,3 \%$ dan pegawai yang berjenis kelamin perempuan sebanyak 5 orang dengan tingkat persentase $53,7 \%$. Adapun jumlah karyawan dapat dilihat pada tabel berikut :

Tabel 1

Jumlah pegawai Berdasarkan Jenis Kelamin

\begin{tabular}{|c|c|c|c|}
\hline No & $\begin{array}{c}\text { Jenis } \\
\text { Kelamin }\end{array}$ & $\begin{array}{c}\text { Jumlah } \\
\text { (orang) }\end{array}$ & $\begin{array}{c}\text { Persentase } \\
(\boldsymbol{\%})\end{array}$ \\
\hline 1 & Laki - laki & 9 & 64,3 \\
\hline 2 & Perempuan & 5 & 53,7 \\
\hline & Jumlah & $\mathbf{1 4}$ & $\mathbf{1 0 0}$ \\
\hline
\end{tabular}

Sumber : data primer diolah

b. Karakteristik Responden Berdasarkan Usia

Berdasarkan hasil penelitian dapat diketahui bahwa, karyawan yang paling banyak memiliki kinerja adalah mereka yang berada pada range usia $<45$ tahun sebanyak 6 orang dengan tingkat persentase $42,8 \%$, diikuti usia $26-35$ tahun dan 36 - 45 Tahun yaitu sebanyak 4 orang dengan tingkat persentase $28,6 \%$, dimana jumlah pegawai dapat dilihat pada tabel berikut :

Tabel 2

Jumlah pegawai Berdasarkan Usia

\begin{tabular}{|c|c|c|c|}
\hline No & Usia & Jumlah & Persenta \\
\hline
\end{tabular}


Sentralisasi Volume 5(2): 15-20 (2016)

Pengaruh Komunikasi Terhadap Kinerja Pegawai Pada Badan .......

Putu Anggeyani Widya Astuty

\begin{tabular}{|c|c|c|c|c|c|c|c|c|c|}
\hline & & (orang) & se $(\%)$ & 2. & 12 & 11 & 144 & 121 & 132 \\
\hline 1 & $<25$ Tahun & - & - & 3. & 12 & 11 & 144 & 121 & 132 \\
\hline & & 4 & 286 & 4. & 11 & 11 & 121 & 121 & 121 \\
\hline 2 & $20-55$ & & 20,0 & 5. & 11 & 11 & 121 & 121 & 121 \\
\hline & $36-45$ & 4 & 286 & 6. & 11 & 11 & 121 & 121 & 121 \\
\hline 3 & To- & 4 & & 7. & 11 & 12 & 121 & 144 & 132 \\
\hline 4 & & & & 8. & 11 & 11 & 121 & 121 & 121 \\
\hline 4 & $>46$ Tahun & 0 & 42,8 & 9. & 11 & 11 & 121 & 121 & 121 \\
\hline & Jumlah & 14 & 100 & 10. & 11 & 11 & 121 & 121 & 121 \\
\hline \multirow{4}{*}{\multicolumn{4}{|c|}{$\begin{array}{l}\text { Sumber : data primer diolah } \\
\text { Karakteristik Responden } \\
\text { Pendidikan } \\
\text { Pendidikan } \\
\text { Berdasarkan pendidikan } \\
\text { memiliki pendidikan SMA }\end{array}$}} & 11. & 10 & 10 & 100 & 100 & 100 \\
\hline & & & & 12. & 11 & 11 & 121 & 121 & 121 \\
\hline & & & & $\begin{array}{l}13 . \\
14\end{array}$ & $\begin{array}{c}11 \\
9\end{array}$ & $\begin{array}{c}11 \\
9\end{array}$ & $\begin{array}{c}121 \\
81\end{array}$ & $\begin{array}{c}121 \\
81\end{array}$ & $\begin{array}{c}121 \\
81\end{array}$ \\
\hline & & & & Jumlah & 154 & 152 & 1702 & 1656 & 1677 \\
\hline
\end{tabular}

orang dengan tingkat persentase $42,8 \%$ dan pendidikan D3 dan sarjana sebanyak 6 orang dengan tingkat persentase $28,6 \%$. Selengkapnya tabulasi data pegawai dapat dilihat pada tabel berikut :

Tabel 3

Jumlah Pegawai Berdasarkan Pendidikan

\begin{tabular}{|c|c|c|c|}
\hline No & $\begin{array}{c}\text { Masa } \\
\text { Kerja }\end{array}$ & $\begin{array}{c}\text { Jumlah } \\
\text { (orang) }\end{array}$ & $\begin{array}{c}\text { Persentase } \\
(\mathbf{\%})\end{array}$ \\
\hline 1 & SD & 0 & 0 \\
\hline 2 & SLTP & 0 & 0 \\
\hline 3 & SMA/SMK & 6 & 42,8 \\
\hline 4 & D3 & 4 & 28,6 \\
\hline 5 & SARJANA & 4 & 28,6 \\
\hline & Jumlah & $\mathbf{1 4}$ & $\mathbf{1 0 0}$ \\
\hline
\end{tabular}

Sumber : Data primer diolah

Berdasakan pedoman analisis, maka angkaangka total pada tabel perolehan nilai yang diperoleh masing-masing responden untuk kedua variabel kemudian dimasukkan kedalam tabel korelasi product moment dengan demikian angka terlihat sebagaimana pada tabel dibawah ini.

\section{Tabel 4}

Korelasi Product Moment

\begin{tabular}{|c|c|c|c|c|c|}
\hline No. & $\mathbf{X}$ & $\mathbf{Y}$ & $\mathbf{X}^{\mathbf{2}}$ & $\mathbf{Y}^{\mathbf{2}}$ & $\mathbf{X Y}$ \\
\hline 1. & 12 & 11 & 144 & 121 & 132 \\
\hline
\end{tabular}

Untuk mendapatkan angka korelasi antara variabel bebas dengan variabel terikat, maka angka-angka pada penjumlahan dimasukan kedalam rumus korelasi product moment yang perhitungannya adalah sebagai berikut :

$$
\begin{aligned}
r & =\frac{n \cdot \sum X Y-\sum X \sum Y}{\sqrt{n \sum X^{2}-\left(\sum X\right)^{2} \cdot n \sum Y^{2}-\left(\sum Y\right)^{2}}} \\
& =\frac{14(1677)-(154) \cdot(152)}{\sqrt{14(1702)-(154) \cdot 14(1656)-(152)^{2}}} \\
& =\frac{23478-23408}{\sqrt{(23828-23716) \cdot(23184-23104)}} \\
& =\frac{70}{\sqrt{(112)(80)}} \\
& =\frac{70}{\sqrt{8960}} \\
& =\frac{70}{94,66} \\
r & =0,74
\end{aligned}
$$

Hasil perhitungan yang diperoleh penulis adalah sebesar 0,74. Yang artinya bahwa ada hubungan yang tinggi sekali antara pengaruh komunikasi terhadap kinerja pegawai pada Badan Kepegawaian Kabupaten Tambrauw. Hubungan yang tinggi tersebut diketahui dari hasil analisis yang memperoleh nilai korelasi 


\section{Sentralisasi Volume 5(2): 15-20 (2016)}

\section{Pengaruh Komunikasi Terhadap Kinerja Pegawai Pada Badan .......}

Putu Anggeyani Widya Astuty

sebesar 0,74, hubungan yang sedemikian menunjukkan bahwa :

1. Apabila terjadi peningkatan sebesar 0,74 pada variabel bebas maka peningkatan yang sama akan terjadi pada variabel terikat yaitu kinerja pegawai.

2. Apabila terjadi penurunan sebesar 0,74 pada variabel bebas yaitu komunikasi, maka penurunan yang sama akan terjadi pada variabel terikat yaitu kinerja pegawai. Kondisi yang demikian ini dapat terjadi dan berlaku dengan asumsi variabel-variabel lainnya diaggap konstan,

\section{KESIMPULAN}

Berdasarkan penelitian diatas maka dapat disimpulkan bahwa :

1. Hasil perhitungan yang diperoleh penulis adalah sebesar 0,74. Yang artinya bahwa ada hubungan yang tinggi sekali antara pengaruh komunikasi terhadap kinerja pegawai pada Badan Kepegawaian Kabupaten Tambrauw.

2. Komunikasi yang efektif merupakan langkah perkembangan suatu organisasi dalam rangka meningkatkan kualitas kinerja pegawai.

3. Pelaksanaan program kerja yang berlangsung tentunya ditunjang dengan cara berkomunikasi yang tepat guna serta sarana komunikasi yang ada dapat membantu pegawai dalam melaksanakan tugas, sehingga dapat mencapai tujuan organisasi.

\section{DAFTAR PUSTAKA}

Anung Ngurah Gusti. 1992. Metode Penelitia Sosial, Pengertian dan Pemakaian Praktis, Penerbit : PT. Gamedia Pustaka Utama Jakarta.

Leon C. Mangginson Dalam A. A. Anwar Prabu Mangkunegara. 2005. Manajemen Sumber Daya Manusia. Penerbit : CV. Alfabeta. Bandung.

Malo Manase. 1986. Metode penelitian Bisnis. Cetakan Kedua.
Pace dan Faules. 2000. Pengantar Komunikasi Dan Informasi, penerbit : Aerlangga. Jakarta.

Peraturan Daerah. 2001. Pegawai Negeri Sipil . tugas Fungsi, kedudukan. Penerbit : Karunika, Univesritas Terbuka Jakarta.

Tata Laksana Kerja BAdan Diklat, Tidak diterbitkan, 2003. UNDANG-Undang Kepegawaian Nomor 43 Tahun 1999. Penerbit : Gajah Mada. Yogyakarta.

Sudyana Nana. 1999. Tuntunan Penyusunan Karya Ilmiah, Makalah, Skripsi, Thesis, Cetakan Kelima. Penerbit Sinar Biru algensido. Bandung. 